\title{
A Method for the Preparation of Heavy-atom Derivatives of Yeast Cytochrome $c$ Peroxidase
}

\begin{abstract}
This Letter describes a strategy for preparation of heavy-atom derivatives which has succeeded with yeast cytochrome $c$ peroxidase and which may be useful for other erystalline proteins. Trunsfer of the crystals from methylpentanediol solu. tions, in which they were grown, to solutions of polyethylene glycol $\left(M_{\mathbf{r}} 6000\right)$ maintains the crystal structure so that crystals tolerate heavy-atom concentrations at least ten times larger than could be attained in methylpentanediol mother liquors.
\end{abstract}

Preparation of heavy-atom derivatives of crystalline proteins is frequently hampered by disordering or dissolution of crystals at the concentrations of heavy atoms sufficient to achieve suitable occupancies of specific sites. Fxcept for -SH ligands, which have very high affinities for cations such as $\mathrm{Hg}^{2+}$, binding sites on crystalline proteins generally display $K_{\mathrm{a}}$ values of the order of $10^{-3} \mathrm{M}^{-1}$ and may require concentrations in the $10 \mathrm{~mm}$ range for derivative preparation (Blundell \& Johnson, 1976).

Difficulties in derivative preparation have been acute in the case of CCP $\uparrow$ crystallized from MPD. Crystals of native CCP suitable for orystallographic analysis are prepared by dialyzing a $1 \%$ enzyme solution in $38 \mathrm{~mm}$-phosphate buffer (pH 5.8), against the same buffer containing 15 to $20 \%$ MPD (Larsson et al., 1970). Mercurial derivative(s), in which mercury is presumably bound by the single cysteine residue (Ellfolk, 1967), can be obtained by soaking crystals for three to five days at mercurial concentrations up to $0.1 \mathrm{~mm}$. Regardless of the nature of the mercurial $(\mathrm{Hg}$ acetate, mersalyl, etc.), these derivatives all contain $\mathrm{Hg}$ at the same major sites. Minor differences among these derivatives, due to low occupancies of other sites, could not be amplified to produce additional heavy-atom isomorphs because the crystals dissolved upon exposure to solutions more concentrated than $0.5 \mathrm{~mm}$. Although increasing the MPD concentration prevented dissolution in the presence of somewhat higher mercurial concentrations, exposure to MPD concentrations greater than $20 \%$ was found to produce non-isotropic disorder in the crystalline packing. Heavy atoms other than mercurials failed to produce significant intensity differences at concentrations in the $0.1 \mathrm{~mm}$ range, and dissolved the CCP crystals if employed at higher concentrations.

The utility of polyethylene glycol as a crystallizing agent (Janssen \& Reulius, 1968 ; Swaney \& Klotz, 1971 ; Epp et al., 1971 ; Ward et al., 1975; McPherson, 1976) prompted us to explore the transfer of CCP crystals from MPD to polyethylene glycol solutions. We have found conditions under which concentrations of heavy atoms as high as $10 \mathrm{mM}$ can be added to CCP crystals, after transfer to polyethylene glycol, without

† Abbreviations used: CCP, cytochrome c peroxidase; MPD, methylpentanediol. 
concomitant disordering or dissolution. Here we wish to report the preparation of a $\mathrm{PtCl}_{4}^{2-}$ derivative of CCP.

Crystals grown in MPD were first transferred to a solution containing acetate buffer $(38 \mathrm{~mm}$ at $\mathrm{pH} \mathrm{5 \cdot 8),5 \%} \mathrm{MPD}$ and approximately $12 \%$ polyethylene glycol $\dagger$. After 24 hours, the crystals were suspended in a solution of the same composition containing $10 \mathrm{mM}-\mathrm{PtCl}_{4}^{2-}$. The second soaking step was performed in a light-tight container to prevent reduction of $\mathrm{Pt}^{\mathrm{II}}$. Crystals soaked in $\mathrm{PtCl}_{4}^{2-}$ for one to three days exhibited the same cell dimensions as native CCP crystals but showed pronounced intensity differences. The use of acetate buffer instead of phosphate buffer results in larger intensity differences, as expected from the studies of Petsko (1973) (cf. Blundell \& Johnson, 1976, pp. 228-229). In contrast, CCP crystals in 15\% MPD and acetate buffer $\left(50 \mathrm{~mm}\right.$ at $\mathrm{pH} \mathrm{5 \cdot 8)}$ were disordered upon exposure to $\mathrm{PtCl}_{4}^{2-}$ at concentrations greater than $0 \cdot 1 \mathrm{~mm}$.

Peaks in difference Patterson syntheses based on projection data indicated that the Pt sites were completely different from the inercurial site. Relative occupancies of four Pt sites, estimated from difference Fouriers and refinement, are: site 1, 1.52; site $2,1 \cdot 36$; site $3,0 \cdot 74$; site $4,0 \cdot 68$.

We presume that polyethylene glycol 6000 , with an estimated "effective" radius of 30 to $35 \AA$ (Edmond \& Ogston, 1968), is unable to penetrate the crystal lattice to any significant extent. The major alteration in the intracrystalline environment on transfer to polyethylene glycol is therefore a reduction in the MPD concentration. We suggest that the dielectric constant of the intracrystalline medium may be the crucial variable in our experiments. It is well known that salting-in of proteins is dependent on $D$ (Cohn \& Ferry, 1943); for a spherical dipolar ion, Kirkwood (1934) showed that the logarithm of the solubility varies as ionic strength times $(1 / D)^{2}$. At $20^{\circ} \mathrm{C}$ the dielectric constant of $20 \% \mathrm{MPD}$ is $70 \cdot 8$, compared with a value of 80.4 for water (Petsko, 1975). Hence crystals in MPD are more likely to dissolve upon addition of heavy-atom salts than are crystals in a medium of higher dielcetric constant. The effect of $D$ on salting-in may be especially pronounced for proteins which crystallize from water at very low ionic strengths, as CCP does (Yonetani et al., 1966). The importance of electrostatic interactions in maintenance of crystalline order, once crystals are removed from very salty solutions, has been stressed by Petsko (1975) and Douzou (1977), who have found that successful transfer of crystals to antifreeze solvents at low temperature requires careful control of the solvent dielectric constant.

The present report is essentially an empirical description. We have not made an exhaustive survey of the stability of CCP crystals as a function of ionic strength, MPD concentration, and polyethylene glycol concentration. The approximately $12 \%$ polyethylene glycol mixture used for preparation of the $\mathrm{Pt}$ derivative contains $5 \%$ MPD because we found that crystals survived better at this polyethylene glycol concentration in the presence of a few per cent of diol. We cannot eliminate the possibility that specific interactions in CCP crystals contribute to the large effects of solvent interchange. However, we hope that the procedure we have described will provide an additional variable which may be exploited to prepare heavy-atom derivatives of other proteins.

† Solutions denoted as approx. $12 \%$ polyethylene glycol were prepared by adding 1 vol. of stock polyethylene glycol 6000 (35 g polyethylene glycol in $100 \mathrm{ml})$ to 2 vol. of buffer. Polyethylene glycol was purified as described by Fried \& Chun (1971). 
Department of Structural Chemistry

Arrhenius Laboratory, University of Stockholm

Fack, S-106 91 Stockholm, Sweden

Biophysics Research Div. I.S.T. Building

University of Michigan

Ann Arbor, U.S.A.

University of Pennsylvania, School of Medicine G3

Department of Biochemistry and Biophysics

Philadelphia, U.S.A.

Rereived 1 September 1978
BirgitTa Eriksson

Bo Ersson

Peder Kierkegaard

LaRs OLOF Larsson

ULF SKOGLUND

Martha LUDWIG

TakashI Yonetani

\section{REFERENCES}

Bhundell, T. L. \& Tohnson, L. N. (1976). Protein Crystallography, Academic Press, Now York.

(ohn, E. J. \& Ferry, J. D. (1943). In Proteins, Amino Acids and Peptides (Cohn, E. J. \& Edsall, J. T., eds), pp. 609-616, Reinhold Press, Now York.

Douzou, P. (1977). Cryobiochemistry, Academic Press, New York.

Edmond, E. \& Ogston, A. G. (1968). Biochem. J. 109, 569-576.

Ellfolk, N. (1967). Acta Chem. Scand. 21, 2736-2742.

Epp, O., Steigemann, W., Formanek, H. \& Huber, R. (1971). Eur. .J. Biochem. 20, 432437.

Fried. M. \& Chtun, P. W. (1971). Methods Enzymol. 22, 242.

.Janssen, J. W. \& Reulius, H. W. (1968). Biochim. Biophys. Acta, 151, 330-342.

Kirkwood, J. G. (1934). J. Chem. Phys. 2, 351-361.

Larsson, L.-O.. Hagman, P., Kierkegaard, P. \& Yonetani, T. (1970). J. Biol. Chem. 245, 902-903.

McPherson, A., Jr (1976). J. Biol. Chem. 251, 6300-6303.

Petsko, G. A. (1973). D. Phil. Thesis, Oxford University.

Petsko, G. A. (1975). .J. Mol. Biol. 96, 381-392.

Swaney, J. B. \& Klotz, I. M. (1971). Arch. Biochem. Biophys, 147, 475-486.

Ward, K., Wishner, B. C., Lattman, E. E. \& Love, W. E. (1975).J. Mol. Biol. 98, 161-177.

Yonetani, T., Chance, B. \& Kajiware, S. (1966). J. Biol. Chem. 241, 2981-2982. 